\title{
SOLD1 is expressed in bovine trophoblast cell lines and regulates cell invasiveness
}

\author{
Mahmoud Awad ${ }^{1,2}$, Katsuo Koshi ${ }^{3}$, Keiichiro Kizaki ${ }^{1,2}$, Toru Takahashi ${ }^{4}$ and Kazuyoshi Hashizume ${ }^{1,2^{*}}$
}

\begin{abstract}
Background: Secreted protein of Ly-6 domain 1 (SOLD1), a secretory-type member of the Ly-6 superfamily, is expressed in both fetal and maternal tissues throughout gestation. SOLD1 mRNA is expressed in the endometrium and in trophoblast mononucleate and binucleate cells, suggesting it plays an important role not only in placental architecture at early gestation, but also in remodeling the endometrium at late gestation. Here, we investigate the expression of SOLD1 mRNA and protein in trophoblast cell lines. In addition, we examine the effect of SOLD1 on the invasive ability of trophoblast cells.

Methods: We measured SOLD1 gene expression in thirteen bovine trophoblast (BT) cell lines by using quantitative reverse transcription PCR (qRT-PCR). SOLD1 protein levels were examined in two cell lines, BT-C and BT-K, by using Western blotting and immunocytochemistry. In addition, we measured the invasive activity of BT cells in the presence or absence of anti-bovine SOLD1 antibodies.

Results: At variable levels, SOLD1 was expressed in all thirteen cell lines; however, expression remained below that of proximal fetal membrane tissue. SOLD1 protein, which was approximately $28 \mathrm{kDa}$ in size, was detected in perinuclear area of the cytoplasm in BT cells. Treatment with anti-bovine SOLD1 antibody had a dose-dependent suppressive effect on the invasiveness of BT-K cell lines.

Conclusions: The present study is the first to investigate SOLD1 expression in vitro, in trophoblastic cell lines. Our data suggested that SOLD1 is involved in the regulation of the trophoblast invasiveness. Therefore, SOLD1 may play an active and crucial role in mediating communication at the fetomaternal interface.
\end{abstract}

Keywords: SOLD1, Placenta, Trophoblast, Ly-6 domain, Cell invasion

\section{Background}

Trophoblastic cells, which arise from the outer layer of blastocyst, are thought to be the first cells to differentiate during embryogenesis [1]. Trophoblast is considered one of the basic fetal compartments that contribute to the formation of the placenta. Bovine placenta is synepitheliochorial, directly contacting maternal endometrial cells at limited sites called placentomes [2]. Bovine trophoblast cells are categorized into two main types, trophoblast mononucleate cells (TMCs) and trophoblast binucleate cells (BNCs) [3,4]. BNCs arise from the differentiation of TMCs through a cytokinetic mitotic division

\footnotetext{
*Correspondence: kazuha@iwate-u.ac.jp

'Laboratory of Veterinary Physiology, Cooperative Department of Veterinary Medicine, Faculty of Agriculture, Iwate University, 3-18-8 Ueda, Morioka, Iwate 020-8550, Japan

${ }^{2}$ United Graduate School of Veterinary Science, Gifu University, Gifu, Japan Full list of author information is available at the end of the article
}

$[4,5]$. Both cell types play a key role during the periimplantation period by secreting various cell type-specific

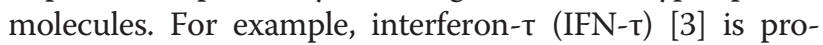
duced by TMCs, and BNCs secrete BCL2-related protein A1 (BCL2A1), an anti-apoptotic factor involved in cell maintenance [6], placental lactogen (CSH1) [7], prolactinrelated proteins (PRPs) [8], and pregnancy-associated glycoproteins (PAGs) [9]. Together, these molecules are important for embryo implantation, maintaining pregnancy, and fetal growth.

Bovine SOLD1, a secreted member of Ly- 6 superfamily, has a Ly-6 domain (lymphocyte antigen-6, Ly-6/urokinasetype plasminogen activator receptor (uPAR)) that consists of 70-100 amino acids characterized by a conserved pattern of 8-10 cysteine residues and a defined pattern of disulfide bonding [10-13]. Previous studies showed that SOLD1 is detected in TMCs at early and mid-gestation, 
and detected in both TMCs and BNCs at late gestation. SOLD1 protein is distributed throughout the villous tree mesenchyme in placentomes and its expression increases in the endometrial epithelium and sub-epithelial stroma as pregnancy progresses, suggesting that SOLD1 plays a key role in placental construction, fetal growth, and fetal membrane expansion during early pregnancy $[10,12,13]$. In addition, SOLD1 is likely involved in the remodeling of the endometrium during late pregnancy [10]. However, the actual physiological function of SOLD1 and the mechanism by which SOLD1 is regulated, remain unclear.

Trophoblast cell lines are considered a convenient tool to elucidate the function of trophoblast-specific molecules that are predicted to play a crucial role during pregnancy. Trophoblast cell lines can also be used to clarify the mechanisms that regulated the function of trophoblast-specific factors. Furthermore, the cell lines can be used to learn more about the cellular characteristics of trophoblast. For these purposes, several cell lines have been established from different species including pigs, mice, and cows [14-18].

For the implantation process to be successful in ruminants, three different steps must be achieved. First, the conceptus elongates prior to implantation. Next, the fetal trophoblastic cell layer opposes and adheres closely to the maternal endometrial epithelial layer. Lastly, the trophoblast cells invade into the endometrial epithelium, resulting in the fusion of maternal and fetal tissues and the initiation of placenta formation [19-21].

The invasion of fetal trophoblast into maternal uterine tissues in humans and mice is considered a critical process in fetal development, providing adequate fetomaternal fixation [22,23]. Throughout bovine gestation, BNCs represent approximately $20 \%$ of the fetal chorionic epithelium. BNCs migrate to the opposed uterine epithelium without passing through the basement membrane. At the interface, BNCs release their granules into uterine epithelium $[24,25]$. In contrast, in sheep, there is restricted invasion that results in the formation of syncytia [26]. In the present study, we investigated the levels of SOLD1 mRNA and protein in BT cell lines, and examined the effect of SOLD1 on the invasiveness of trophoblastic cells in vitro.

\section{Methods}

\section{Cell culture}

Thirteen BT cell lines (BT-1 and BT-A-L) were established from in vitro matured and in vitro fertilized blastocysts as described previously $[18,27]$. The BT cell lines were cultured and maintained according to a previously described method [28]. In brief, the cells were cultured in Dulbecco's modified Eagle's medium/F-12 medium (Sigma, Saint Louis, MI, USA) containing $100 \mathrm{IU} / \mathrm{ml}$ of penicillin and $100 \mu \mathrm{g} / \mathrm{ml}$ of streptomycin (Sigma), supplemented with $10 \%$ fetal bovine serum (FBS; Biowest, Nuaillé, France), at $37^{\circ} \mathrm{C}$ in an atmosphere of $5 \% \mathrm{CO}_{2}$. The medium was changed every 2-3 d. A monolayer of confluent BT cells was mechanically passaged by pipetting. Collagen-coated flasks were prepared by incubating flasks with acid-soluble porcine type I collagen ( $3 \mathrm{mg} / \mathrm{ml}$ of type I-C collagen; Nitta Gelatin Osaka, Japan), diluted 10-fold with distilled water and poured into flasks for more than an hour. Flasks were then washed with general culture medium. After a phosphate-buffered saline (PBS) wash, dissociated cell aggregates were plated in the collagencoated flasks. The cell cultures grown in collagen-coated flasks were used for RNA purification, Western blotting, or immunocytochemistry. BT-1 was used as a standard cell line because it was maintained and monitored for more than 300 passages, and may show features of stable trophoblastic cells.

\section{RNA extraction and RT-PCR}

Total RNA was isolated from the cultured cells and bovine proximal fetal membranes (PFM) using TRIzol Reagent (Invitrogen, Carlsbad, CA, USA) according to the manufacturer's instructions. The yield of total RNA was quantified by measuring the absorbance at $260 \mathrm{~nm}\left(\mathrm{~A}_{260}\right)$. RNA quality was determined by measuring the $A_{260} / A_{280}$ ratio using a NanoDrop spectrophotometer (ND-1000, Wilmington, DE, USA) and by using $1 \%$ agarose gel electrophoresis. Genomic DNA was removed using DNase and the TURBO DNA-free Kit (Ambion, Austin, TX, USA). Two micrograms of total RNA was reversetranscribed into cDNA using random primers and a highcapacity reverse transcription kit (Applied Biosystems, Foster City, CA, USA) according to the manufacturer's instructions. The reverse transcription (RT) cycle conditions were as follows: $25^{\circ} \mathrm{C}$ for $10 \mathrm{~min}, 37^{\circ} \mathrm{C}$ for $120 \mathrm{~min}$, and $85^{\circ} \mathrm{C}$ for $5 \mathrm{~s}$. The resultant cDNA was stored at $-20^{\circ} \mathrm{C}$. Each PCR reaction contained cDNA template, primers (Table 1), and AmpliTaq Gold PCR Master Mix (Applied Biosystems). The PCR reaction was performed as follows: $95^{\circ} \mathrm{C}$ for $30 \mathrm{~s}$ for denaturation, $57^{\circ} \mathrm{C}$ for $30 \mathrm{~s}$ for annealing, and $72^{\circ} \mathrm{C}$ for $1 \mathrm{~min}$ for extension, repeated for 26 cycles. The PCR products were analyzed using agarose gel electrophoresis and visualized by ethidium bromide staining. The amplified products were subcloned into the pGEM-T Easy vector (Promega, Madison, WI, USA) and sequenced using a BigDye Terminator cycle sequencing kit and an automated sequencer (Applied Biosystems).

\section{Quantitative RT-PCR}

The level of SOLD1 mRNA in the BT cell lines and PFM were confirmed by qRT-PCR by using a SYBR Green assay (Applied Biosystems) as described previously [29]. The primer pairs used for qRT-PCR are described in a previous study [29] (Table 2). The relative differences in 
Table 1 Primers used for RT-PCR analysis

\begin{tabular}{llll}
\hline Gene & Primer & Sequence & Position \\
\hline SOLD1 [NM_001105478] & F & $5^{\prime}$-TCCAGAGATGGCTAAGTGCCTT-3' & $50-71$ \\
& $R$ & $5^{\prime}$-GAGTGGACATGACTGAGCCAC-3' & $453-432$ \\
GAPDH [NM_001034034] & $F$ & $5^{\prime}$-CCTTCATTGACCTTCACTACATGGTCTA-3' & $173-201$ \\
& $R$ & $5^{\prime}$-GCTGTAGCCAAATTCATTGTCGTACCA-3' & $1029-1002$ \\
\hline
\end{tabular}

the initial levels of each cDNA species were determined by comparing their threshold cycle $(\mathrm{Ct})$ values. To quantify the mRNA copy number, a standard curve was generated for each gene by using serial dilutions of plasmids containing the corresponding cDNAs. The dissociation curve used to detect the SYBR green-based amplicons of interest was accurate, because SYBR green also detects double-stranded DNA, including primer dimers, contaminating DNA, and PCR products from misannealed primers. Contaminating DNA and primer dimers appeared as separate peaks from the desired amplicon peak. For each gene, the ratio of its mRNA expression level to that of glyceraldehyde-3-phosphate dehydrogenase $(G A P D H)$ was calculated to adjust for variations among the qPCR reactions. All values are presented as the mean \pm standard error of the mean (SEM).

\section{Western blot analysis}

Western blots were performed as previously described [18]. SOLD1 protein was extracted from BT-C and BT-K cell lines (cell lysates and/or conditioned media). Briefly, cells were cultured until they reached confluence and washed using serum-free media, followed by PBS. Cells were homogenized in lysis buffer containing $50 \mathrm{mM}$ Tris (pH 7.5), $150 \mathrm{mM} \mathrm{NaCl}, 0.1 \%$ Triton X-100, and Complete, Mini protease inhibitor cocktail (Roche Diagnostic $\mathrm{GmbH}$, Mannheim, Germany). After centrifugation at $15800 \times g$ for $15 \mathrm{~min}$ at $4^{\circ} \mathrm{C}$, the supernatant was collected and reserved for further analysis. BT-C and BT-K cell lines were cultured on cell culture inserts $(8-\mu \mathrm{m}$ pore size, BD Biosciences) in 12-well plates. Cells were incubated in serum-free medium in the upper and lower chamber for $48 \mathrm{hrs}$. The upper and lower conditioned media were collected and cold acetone was added (1:4). After an overnight incubation at $-30^{\circ} \mathrm{C}$, the conditioned media was centrifuged and the supernatant was immediately replaced with PBS to dissolve the protein. The concentration of total protein from cell lysates and conditioned media was analyzed using the Quick Start Bradford Protein Assay Kit (Bio-Rad Laboratories, Hercules, CA, USA). The proteins of the cell lysate and conditioned media ( $8 \mu \mathrm{g}$ and $3 \mu \mathrm{g}$, respectively), were separated using $12 \%$ sodium dodecyl sulfate polyacrylamide gel electrophoresis and transferred to PVDF membranes (Immobilon-P, Millipore Corporation, Bedford, MA, USA). The membranes were blocked with $10 \%$ skim milk overnight at $4^{\circ} \mathrm{C}$ and incubated with custom-made bovine anti-bSOLD1 antibody (1:1000) [12] for $1 \mathrm{~h}$ at room temperature. Membranes were subsequently incubated with alkaline phosphatase-conjugated anti-rabbit IgG (1:3000; Sigma) for $1 \mathrm{~h}$ at room temperature. An alkaline phosphatase detection system (Bio-Rad Laboratories) was used to detect immunoreactive SOLD1.

\section{Immunocytochemistry}

BT-C and BT-K cells were cultured for $8 \mathrm{~d}$ in covered 2-well Lab-Tek Chamber slides (Lab-Tek, \#177429) precoated with collagen (as above). After the cells had reached confluence, the slides were fixed using $4 \%$ paraformaldehyde in $0.1 \mathrm{M}$ PBS ( $\mathrm{pH} 7.4$ ) for $30 \mathrm{~min}$ and then incubated with anti-SOLDlantibody (1:200) [12] or normal rabbit serum for 2 hrs at room temperature. After being washed in PBS with Triton X-100 (PBST), the slides were incubated with secondary antibody (Alexa

Table 2 Primers used for qRT-PCR analysis

\begin{tabular}{|c|c|c|c|}
\hline Gene & Primer & Sequence & Position \\
\hline \multirow[t]{2}{*}{ SOLD1 [NM_001105478] } & $\mathrm{F}$ & 5'-GGAAGCACCTGCCAGACTCA-3' & $177-196$ \\
\hline & $\mathrm{R}$ & 5'-AAAGCGTGCCATTTTCGAAG-3' & $246-227$ \\
\hline \multirow[t]{2}{*}{ TNF- $\boldsymbol{a}\left[\mathrm{NM} \_174662\right]$} & $\mathrm{F}$ & 5'-AAGCCGGTAGCCCACGTT-3' & $297-314$ \\
\hline & $\mathrm{R}$ & 5'-TGAGGGCATTGGCATACGA-3' & $375-357$ \\
\hline \multirow[t]{2}{*}{ BCL2A1 [NM_001037100] } & $\mathrm{F}$ & 5'-TTGCAGATACAGCAACCTGGAT-3' & $73-94$ \\
\hline & $\mathrm{R}$ & 5'-GGACAGAGGAAGCCACATCTTG-3' & $145-124$ \\
\hline \multirow[t]{2}{*}{ GAPDH [NM_001034034] } & $\mathrm{F}$ & 5'-AAGGCCATCACCATCTTCCA-3' & $280-299$ \\
\hline & $\mathrm{R}$ & 5'-CCACCACATACTCAGCACCAGCAT-3' & $355-332$ \\
\hline
\end{tabular}

SOLD1, secreted protein of Ly- 6 domain 1; TNF-a, Tumor necrosis factor $a$; BCL1A1, Bcl-2-related protein A1; GAPDH, glyceraldehyde 3-phosphate dehydrogenase; $\mathrm{F}$, forward; $\mathrm{R}$, reverse; $\mathrm{qRT}-\mathrm{PCR}$, quantitative reverse transcription polymerase chain reaction. 
Fluor 488 donkey anti-rabbit IgG; $1: 1000$ in PBST; Invitrogen). To visualize the nuclei, the slides were mounted in Dako fluorescent mounting medium (Dako North America, Inc., Carpinteria, CA) after stained with Hoechst 33342 (Invitrogen). The immunoreactive signals were examined using an ECLIPSE 80i microscope (Nikon, Tokyo, Japan).

\section{Invasion assay}

BT-K and BT-C cell invasion was assessed using a 24-well plate BD BioCoat Matrigel Invasion Chamber (BD Biosciences, Bedford, MA). Inserts contained polyethylene terephthalate membranes $(8-\mu \mathrm{m}$ pore size) coated with a thin layer of Matrigel and a reconstituted basement membrane that prevented non-invasive cells from migrating through the pores of the membrane. Invasive cells were able to detach, invade, and migrate through the Matrigel-coated membrane. Experiments were performed according to manufacturer's instructions. BT-C $\left(2.42 \times 10^{4}\right)$ and BT-K cells $\left(2.25 \times 10^{4}\right)$ were trypsinized, counted, and resuspended in serum-free media. To each well, $750 \mu \mathrm{l}$ of medium containing 10\% FBS (the chemoattractant) was added. In the upper well, $500 \mu \mathrm{l}$ of cell suspension was loaded. The plate was incubated for $6 \mathrm{~d}$ at $37^{\circ} \mathrm{C}$ in humidified air containing $5 \% \mathrm{CO}_{2}$. After the incubation period, the non-invading cells were removed from the upper surface of the filters by using a cottontip applicator. The cells on the lower surface of the Matrigel were fixed in 100\% methanol, stained using $0.5 \%$ hematoxylin, and counted in 4 random highpower $(40 \times)$ fields using an ECLIPSE $80 \mathrm{i}$ microscope (Nikon, Tokyo, Japan). This procedure was repeated in the presence of anti-bSOLD1 antibody. Anti-bSOLD1 antibody $(1: 100,1: 500$, and $1: 1000)$ was added to the serum-free media in the upper part of the Matrigel invasion chamber.

\section{Statistical analysis}

The values are presented as the mean \pm SEM. The qRT-PCR was performed twice for each animal sample, and each experiment was performed in triplicate. All qRT-PCR data were analyzed using one-way analysis of variance, followed by the Turkey-Kramer test or $t$-test. JMP 7 software (SAS Institute Inc, Cary, NC, USA) was used for the analysis. Differences were considered significant at $\mathrm{P}<0.05$.

\section{Results}

SOLD1 mRNA expression in bovine trophoblast cell lines The expression of SOLD1 mRNA was analyzed in thirteen BT cell lines and PFM samples by using qRT-PCR. Every BT cell line expressed SOLD1 mRNA, but at variable levels. Notably, the expression level of SOLD1 in all the BT cell lines tested was below that in PFM samples (Figure 1A). With the exception of BT-1, the BT-K and BT-C cell lines showed the highest and lowest expression of SOLD1, respectively (Figure 1B).

\section{Localization of SOLD1 protein in BT cell lines}

SOLD1 protein was detected in both BT-C and BT-K cell lines by using Western blotting and immunocytochemistry. SOLD1 protein (approximately $28 \mathrm{kDa}$ ) was evident in the lysates and upper/lower conditioned media of both cell lines (Figure 2). Moreover, immunostaining showed that SOLD1 protein was localized to the perinuclear area of the cytoplasm in BT-C and BT-K cells (Figure 3).

\section{The effect of anti-bSOLD1 antibody on the invasiveness of BT cell lines}

We examined the invasive ability of two BT cell lines, BT-C and BT-K. BT-K cells were found to have greater invasiveness than BT-C cells (Figure 4A). To investigate whether there was a relationship between the invasiveness of the BT cells and SOLD1 expression, BT-C and BT-K were treated with anti-bSOLD1 antibodies at three different dilutions. The data showed that no significant differences existed between the untreated groups and their corresponding treated groups for either cell line. Interestingly, anti-bSOLD1 antibodies significantly suppressed the invasive ability of BT-K but not BT-C cells at a high concentration (1:100) in comparison to the other treated groups. The suppression of cell invasiveness of BT-K cells by anti-bSOLD1 was dose-dependent (Figure 4B).

\section{Discussion}

To our knowledge, the present study is the first to report the expression of SOLD1 mRNA and its protein localization in BT cell lines. Furthermore, this study is the first showing the effect of SOLD1 on the invasive ability of BT cell lines. Our results revealed that the BT cells showed different levels of SOLD1 mRNA. BT-K and BT-C cell lines, other than BT-1, that expressed the highest and lowest SOLD1 mRNA levels, respectively, were used for subsequent analyses. SOLD1 protein was detected in the perinuclear area of the cytoplasm in both BT-C and BT-K cell lines. Lastly, BT-K cells showed greater invasive ability than BT-C cells and the invasiveness of BT-K cells was suppressed by antibSOLD1 antibody treatment.

Trophoblast cells that line the external surface of the fetal chorioallantois are derived from the outer blastomeres and can be divided into two distinct populations, TMCs and BNCs $[3,24,30]$. Both cells secrete several important molecules that are important for implantation and placenta formation. TMCs produce IFN-t [31-33], the maternal recognition molecule of pregnancy. BNCs, 

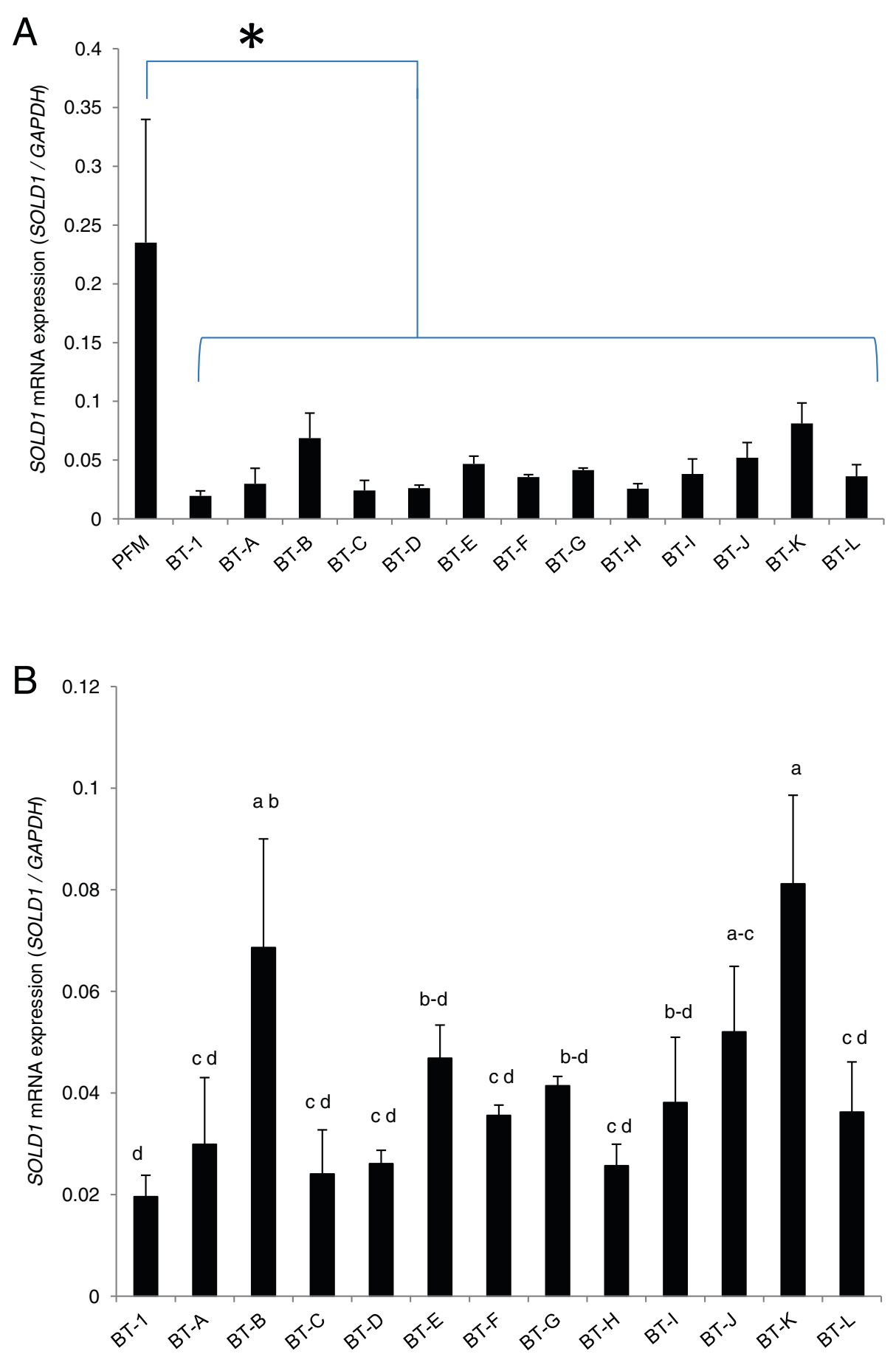

Figure 1 Expression of SOLD1 mRNA. (A) The expression levels of secreted protein of Ly- 6 domain 1 (SOLD1) in bovine trophoblast (BT) cell lines (BT-A-L) in comparison with those in proximal fetal membranes (PFM), an in vivo control, and in BT-1, which was previously established, were analyzed by quantitative reverse transcription PCR (qRT-PCR). (B) The expression level of SOLD1 in BT cell lines. Expression of these mRNAs was normalized to the expression of GAPDH measured in the corresponding RNA preparation. The bar graph shows the means \pm SEM values. Bars labeled with an asterisk (A) and different letters $(\mathbf{B})$ are significantly different from each other $(P<0.05)$.

which differentiate from TMCs by karyokinesis without cytokinesis [34] or endoreduplication [28,35], represent approximately $15-20 \%$ of the total trophoblast population throughout gestation [36]. BNCs secrete various molecules including SOLD1, progesterone, estrogen, CSH1, PRPs, PAGs and others [10,37-41]. In cows, sheep, and goats, BNCs function primarily at the fetomaternal border, where they migrate from the fetal 


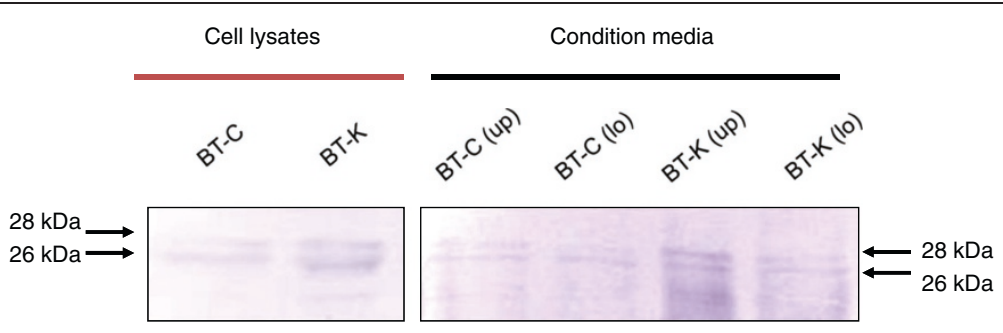

Figure 2 SOLD1 protein levels in BT-C and BT-K cell lines. The upper (up) and lower (lo) conditioned medium and BT-C and BT-K cell lysates were analyzed by Western blot. Arrows indicate SOLD1 bands that are $26 \mathrm{kDa}$ and $28 \mathrm{kDa}$ in size.

trophoblast to the uterine epithelium and fuse to form hybrid cells or syncytia $[4,5,36]$. This process is required to connect fetal compartments to the maternal circulatory system and to allow BNCs to release their cytoplasmic granules, which contains mediators, (e.g. placental lactogen) directly to the maternal side [4].

Analysis of the fetomaternal interface around the time of implantation is crucial to ensure the success of pregnancies; however, the mechanisms underlying fetomaternal interactions remain unclear. In vitro methods may serve as a tool for examining this complex interaction. Trophoblast cells are essential for fetal development and the maintenance of pregnancy in numerous species $[14,16,17,27,42-46]$. Recently, we developed BT cell lines derived from in vitro fertilized (IVF) blastocysts using bone morphogenetic protein 4 . These cells were maintained for approximately 50 passages and exhibited characteristic trophoblast features. According to trophoblast gene expression profiles, these $\mathrm{BT}$ cell lines expressed the BNC-specific factors CSH1, PAG, and PRP, the TMC marker IFN- $\tau$, and SOLD1 $[10,12,13]$. Various molecules derived from trophoblastic cells have been examined in a number of studies; however, information pertaining to SOLD1 remains limited $[10,12,13]$. SOLD1 belongs to the Ly- 6 superfamily of secreted factors and is exclusively found in the female reproductive system and placenta $[12,13]$. We found that SOLD1 mRNA was present in all BT cell lines, but at different levels. These data are in accordance with previous studies showing that SOLD1 was detected in both trophoblast cell types [10]. In previous studies, SOLD1 protein was detected in BT-1 cell lysates, but not in conditioned media when cells were cultured on collagen-coated plates [12]. In contrast, we detected SOLD1 protein, in cell lysates and in conditioned media (upper and lower) from BT-C and BT-K cell lines by using an insert culture system. We attribute these conflicting results to the fact that SOLD1 has specific binding to the telopeptide in fibrillar type I collagen and, to a lesser extent, towards the reticular type III collagen [12]. SOLD1 secreted from trophoblast cells directly binds to the collagen coating of typical culture plates; however, we used an insert culture system that allowed SOLD1 protein to remain free in the conditioned media. SOLD1 immunoreactive signals were localized to the perinuclear area of the cytoplasm in both BT-C and BT-K cell lines, a pattern similar to that of other family members [47].

SOLD1 mRNA levels were not changed by culturing cells on different substrates (collagen coat, collagen gel and Matrigel) for a more than a week ( $8 \mathrm{~d}$ ) (Additional file 1: Figure S1A). However, Matrigel stimulated expression in long-term cultures $(20 \mathrm{~d})$, but not in the presence of collagen coat and collagen gel (Additional file 1: Figure S1B). Matrigel contains various cytokines, and supplies a suitable environment for cellular activities [48]. Although these different phenomena (long-term culture on different matrices) implicate the involvement of apoptotic process, the expression of the apoptosis-related molecules, tumor necrosis factor $\alpha$ (TNF- $\alpha$ ) and BCL2A1, showed no relation to SOLD1 expression even after 3 weeks of culture. In particular, Matrigel culture maintained cell activities and induced differentiation, as indicated by the expression of CSH1, PRPs, PAGs [49] (Additional file 2: Figure S2). Based on that, we hypothesized that SOLD1 is regulated by some cytokines and scaffold conditions; however, the effect of Matrigel on SOLD1 expression remains to be examined. Other specific features of trophoblastic cells are migration and invasion, which are crucial and characteristic placental processes in different species, including humans, mice [23], and horses [50]. During placentation in ruminants, including cows, trophoblastic cells first become apposed to the endometrial epithelia, and then BNCs migrate to the maternal side and fuse with epithelia [41].

In the present study, we found that SOLD1 induced trophoblast invasion. Its activity may be supported by the trophoblastic cells themselves and maternal side production of SOLD1, as suggested by our previous work showing that SOLD1 is detected in cells on both sides of fetomaternal interface [10]. Several growth factors, including fibroblast growth factor 7 and its receptor, have been detected in fetal trophoblast, suggesting paracrine cell-cell interactions [51]. We hypothesized that SOLD1 becomes localized on both sides of the interface through a similar mechanism. Alternatively, SOLD1 might cross 


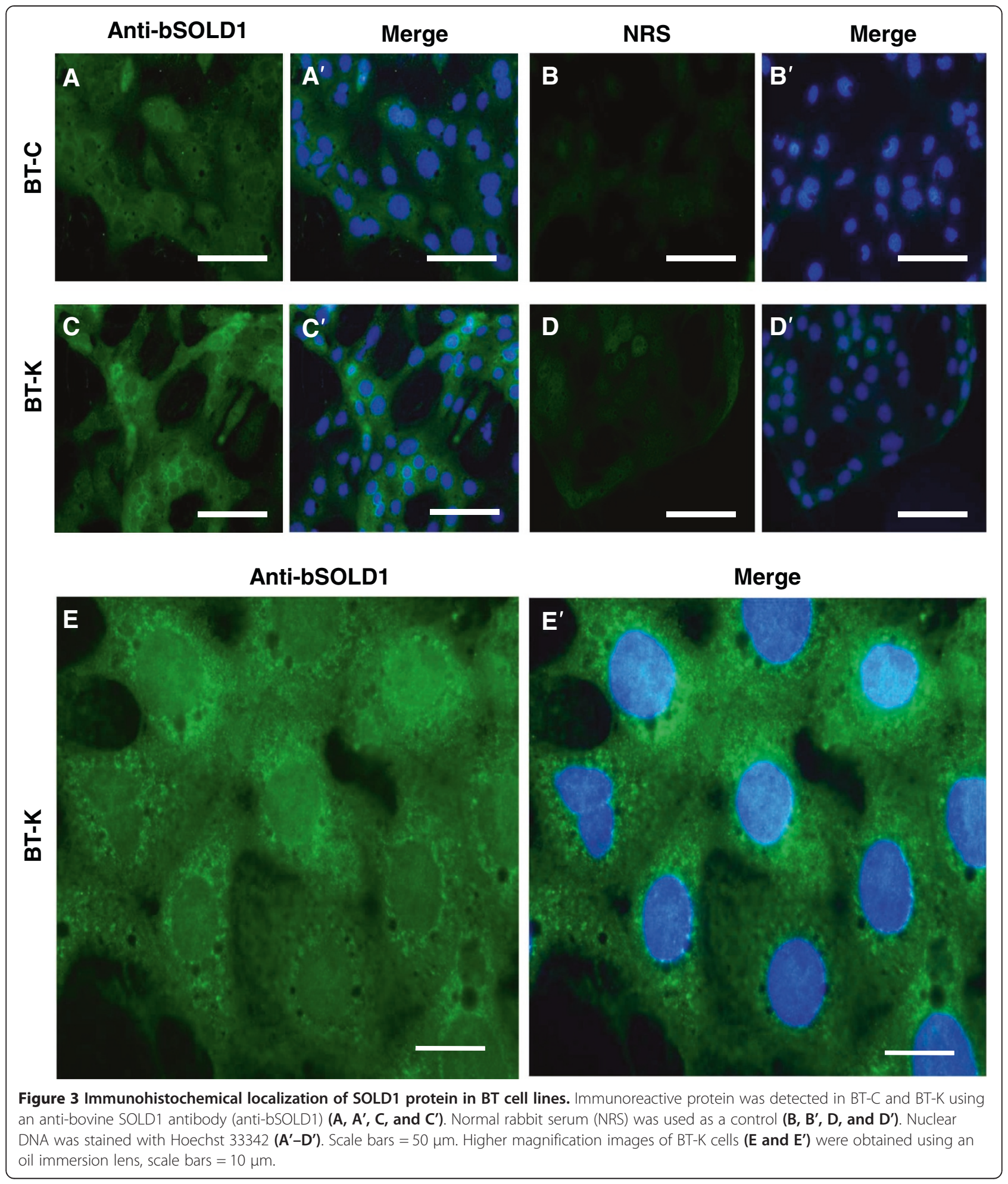

to the maternal side through migration and restricted invasion of BNCs that fuse with the uterine epithelium, forming hybrid cells. In our study, the invasion assay revealed that SOLD1 is involved in the regulation of BT cell invasiveness.

\section{Conclusions}

We have analyzed the expression level of SOLD1 in BT cell lines, a suitable in vitro model for bovine placental trophoblast. SOLD1 was expressed by all the BT cell lines we examined, but at variable levels. In the BT cell 


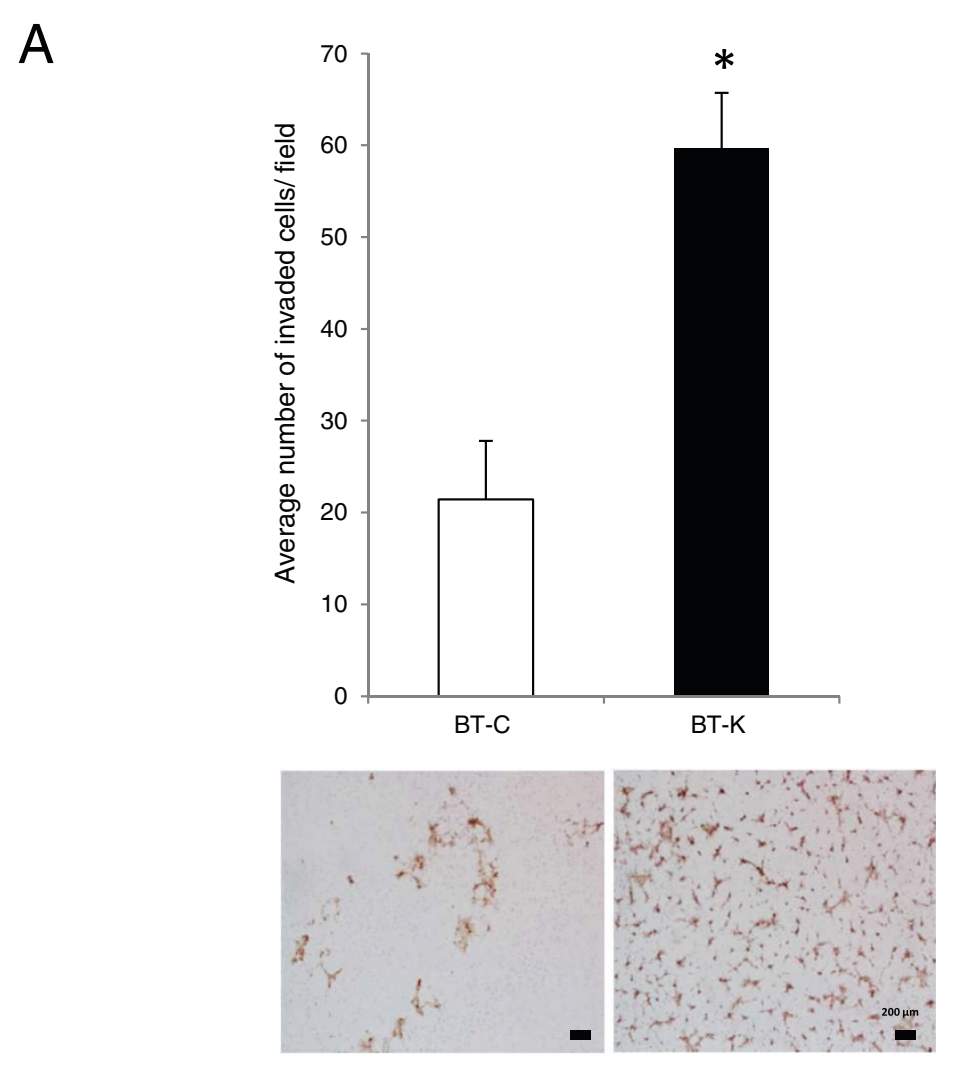

B

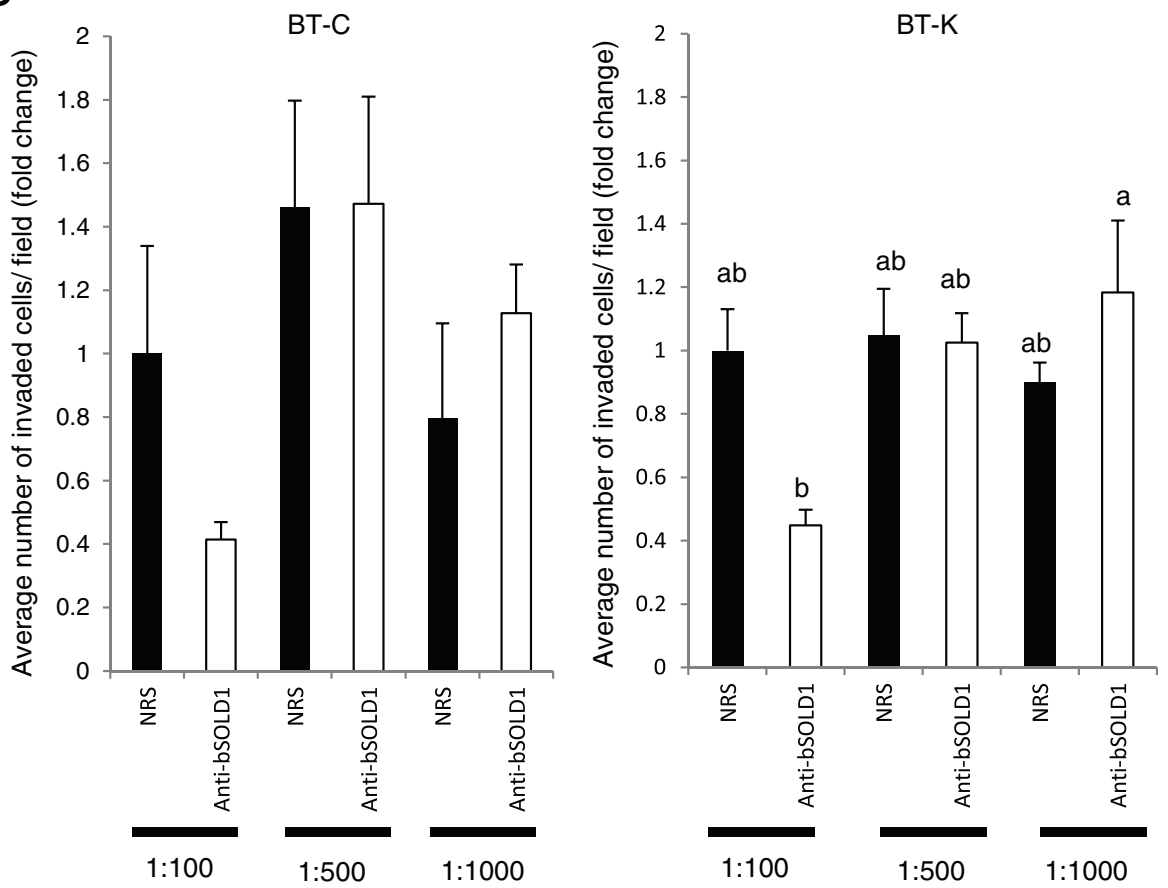

Figure 4 Invasiveness of BT-C and BT-K cells. (A) The invasive ability of BT-C and BT-K cells was measured using Matrigel invasion chamber assay. Hematoxylin staining was used for staining the invaded cells. Scale bars $=200 \mu \mathrm{m}$. (B) The invasion of BT-C and BT-K cells treated with different dilution of anti-bSOLD1 antibody (1:100, 1:500, and 1:1000). Fold change was calculated by dividing each value by the average value in NRS (1:100). The asterisk $(\mathbf{A})$ and different letters $(\mathbf{B})$ indicate values that are significantly different from each other $(P<0.05)$. 
lines, the expression level SOLD1 was below that of fetal membrane tissues. Excluding the formerly established BT-1 cell line, BT-K and BT-C cells had the highest and lowest SOLD1 levels, respectively, of the lines examined. In a dose-dependent manner, anti-bSOLD1 antibodies suppressed the invasiveness of BT-K but not of BT-C cells. Together, these data suggested that SOLD1 is involved in the regulation of trophoblast migration and invasion at the fetomaternal interface.

\section{Additional files}

Additional file 1: Figure S1. SOLD1 expression in cells cultured on different substrates. (A) BT-C and BT-K were cultured on three different substrates, collagen coat (control), collagen gel, and Matrigel, for the normal culture period ( $8 \mathrm{~d}$ ). (B) BT-C cells were cultured on the same substrates for a longer time (20 d). The results were normalized to GAPDH mRNA expression and represented as fold-change values, calculated by dividing each value by the average value on day 4 . The data shows the means \pm SEM. The black bars, gray bars, and white bars represent the control, collagen gel, and Matrigel cultures, respectively. The different letters indicate a significant difference compared with the control $(P<0.05)$.

Additional file 2: Figure S2. TNF- $a$ and $B C L 2 A 1$ expression on different substrates. BT-C was culture on three different substrates, collagen coat (control), collagen gel, and Matrigel, for 20 days. Expression levels of tumor necrosis factor a (TNF-a) and BCL2-related protein A1 (BCL2A1) were normalized to the expression of GAPDH, measured in the corresponding RNA preparation. The black bars, gray bars, and white bars represent the control, collagen gel, and Matrigel cultures, respectively. The different letters indicate a significant difference compared with the control $(P<0.05)$.

\section{Competing interests}

The authors declare that they have no competing interests.

\section{Authors' contribution}

MA planned the study, carried out experiments, and drafted the manuscript. KaK helped in performing the analysis. Ke.K. collected samples and conducted experiments. TT collected samples, raised the anti-SOLD1 antibody, and contributed to discussions. KH designed the experiments, prepared samples, and helped to write the manuscript. All authors read and approved the final manuscript.

\section{Acknowledgements}

This research was supported by grants (Kiban-kenkyu C 24580419; Kiban-kenkyu B 23380162) from the Ministry of Education, Culture, Sport, Science, and Technology of Japan.

\section{Author details}

'Laboratory of Veterinary Physiology, Cooperative Department of Veterinary Medicine, Faculty of Agriculture, Iwate University, 3-18-8 Ueda, Morioka, Iwate 020-8550, Japan. ${ }^{2}$ United Graduate School of Veterinary Science, Gifu University, Gifu, Japan. ${ }^{3}$ Tokyo Metropolitan Institute of Gerontology, Tokyo, Japan. ${ }^{4}$ Cooperative Department of Veterinary Medicine, Faculty of Agriculture, Iwate University, Morioka 020-8550, Japan.

Received: 8 March 2014 Accepted: 17 June 2014

Published: 21 June 2014

\section{References}

1. Handyside AH, Johnson MH: Temporal and spatial patterns of the synthesis of tissue-specific polypeptides in the preimplantation mouse embryo. J Embryol Exp Morphol 1978, 44:191-199.
2. Schlafer DH, Fisher PJ, Davies CJ: The bovine placenta before and after birth: placental development and function in health and disease. Anim Reprod Sci 2000, 60-61:145-160.

3. Igwebuike UM: Trophoblast cells of ruminant placentas-a minireview. Anim Reprod Sci 2006, 93:185-198.

4. Wooding FBP, Flint APF: Placentation. In Marshall's Physiology of Reproduction, Volume 3. 4th edition. Edited by Lamming GE. London: Chapman and Hall; 1994:233-460.

5. Klisch K, Pfarrer C, Schuler G, Hoffmann B, Leiser R: Tripolar acytokinetic mitosis and formation of feto-maternal syncytia in the bovine placentome: different modes of the generation of multinuclear cells. Anat Embryol (Berl) 1999, 200:229-237.

6. Ushizawa K, Takahashi T, Kaneyama K, Hosoe M, Hashizume K: Cloning of the bovine antiapoptotic regulator, $\mathrm{BCL2}$-related protein $\mathrm{A} 1$, and its expression in trophoblastic binucleate cells of bovine placenta. Biol Reprod 2006, 74:344-351.

7. Gootwine E: Placental hormones and fetal-placental development. Anim Reprod Sci 2004, 82-83:551-566.

8. Yamada O, Todoroki J, Kizaki K, Takahashi T, Imai K, Patel OV, Schuler LA, Hashizume K: Expression of prolactin-related protein I at the fetomaternal interface during the implantation period in cows. Reproduction 2002, 124:427-437.

9. Green JA, Xie S, Quan X, Bao B, Gan X, Mathialagan N, Beckers JF, Roberts RM: Pregnancy-associated bovine and ovine glycoproteins exhibit spatially and temporally distinct expression patterns during pregnancy. Biol Reprod 2000, 62:1624-1631.

10. Awad M, Kizaki K, Takahashi T, Hashizume K: Dynamic expression of SOLD1 in bovine uteroplacental tissues during gestation. Placenta 2013, 34:635-641.

11. Ploug M, Ellis V: Structure-function relationships in the receptor for urokinase-type plasminogen activator. Comparison to other members of the Ly-6 family and snake venom alpha-neurotoxins. FEBS Lett 1994, 349:163-168.

12. Ushizawa K, Takahashi T, Hosoe M, Kizaki K, Hashizume K: Characterization and expression analysis of SOLD1, a novel member of the retrotransposon-derived Ly- 6 superfamily, in bovine placental villi. PLoS One 2009, 4:e5814

13. Ushizawa K, Takahashi T, Hosoe M, Kizaki K, Hashizume K: Cloning and expression of SOLD1 in ovine and caprine placenta, and their expected roles during the development of placentomes. BMC Dev Biol 2010, 10:9.

14. Tanaka S, Kunath T, Hadjantonakis AK, Nagy A, Rossant J: Promotion of trophoblast stem cell proliferation by FGF4. Science 1998, 282:2072-2075.

15. Flechon JE, Laurie $S$, Notarianni E: Isolation and characterization of a feeder-dependent, porcine trophectoderm cell line obtained from a 9-day blastocyst. Placenta 1995, 16:643-658

16. Talbot NC, Caperna TJ, Edwards JL, Garrett W, Wells KD, Ealy AD: Bovine blastocyst-derived trophectoderm and endoderm cell cultures: interferon tau and transferrin expression as respective in vitro markers. Biol Reprod 2000, 62:235-247.

17. Shimada A, Nakano H, Takahashi T, Imai K, Hashizume K: Isolation and characterization of a bovine blastocyst-derived trophoblastic cell line, BT-1: development of a culture system in the absence of feeder cell. Placenta 2001, 22:652-662.

18. Suzuki Y, Koshi K, Imai K, Takahashi T, Kizaki K, Hashizume K: Bone morphogenetic protein 4 accelerates the establishment of bovine trophoblastic cell lines. Reproduction 2011, 142:733-743.

19. Imakawa K, Chang KT, Christenson RK: Pre-implantation conceptus and maternal uterine communications: molecular events leading to successful implantation. J Reprod Dev 2004, 50:155-169.

20. Spencer TE, Johnson GA, Bazer FW, Burghardt RC: Implantation mechanisms: insights from the sheep. Reproduction 2004, 128:657-668

21. Guillomot M: Cellular interactions during implantation in domestic ruminants. J Reprod Fertil Suppl 1995, 49:39-51.

22. Huppertz B, Kertschanska S, Demir AY, Frank HG, Kaufmann P: Immunohistochemistry of matrix metalloproteinases (MMP), their substrates, and their inhibitors (TIMP) during trophoblast invasion in the human placenta. Cell Tissue Res 1998, 291:133-148.

23. Pijnenborg R, Robertson WB, Brosens I, Dixon G: Review article: trophoblast invasion and the establishment of haemochorial placentation in man and laboratory animals. Placenta 1981, 2:71-91.

24. Wooding FB, Wathes DC: Binucleate cell migration in the bovine placentome. J Reprod Fertil 1980, 59:425-430. 
25. Wooding FB, Morgan G, Monaghan S, Hamon M, Heap RB: Functional specialization in the ruminant placenta: evidence for two populations of fetal binucleate cells of different selective synthetic capacity. Placenta 1996, 17:75-86.

26. Wooding FB, Chambers SG, Perry JS, George M, Heap RB: Migration of binucleate cells in the sheep placenta during normal pregnancy. Anat Embryol (Berl) 1980, 158:361-370.

27. Hashizume K, Shimada A, Nakano H, Takahashi T: Bovine trophoblast cell culture systems: a technique to culture bovine trophoblast cells without feeder cells. Methods Mol Med 2006, 121:179-188.

28. Nakano H, Shimada A, Imai K, Takezawa T, Takahashi T, Hashizume K Bovine trophoblastic cell differentiation on collagen substrata: formation of binucleate cells expressing placental lactogen. Cell Tissue Res 2002, 307:225-235.

29. Koshi K, Ushizawa K, Kizaki K, Takahashi T, Hashizume K: Expression of endogenous retrovirus-like transcripts in bovine trophoblastic cells. Placenta 2011, 32:493-499.

30. Ward JW, Wooding FB, Fowden AL: The effects of cortisol on the binucleate cell population in the ovine placenta during late gestation. Placenta 2002, 23:451-458.

31. Godkin JD, Bazer FW, Roberts RM: Ovine trophoblast protein 1, an early secreted blastocyst protein, binds specifically to uterine endometrium and affects protein synthesis. Endocrinology 1984, 114:120-130.

32. Bazer FW, Spencer TE, Ott TL: Interferon tau: a novel pregnancy recognition signal. Am J Reprod Immunol 1997, 37:412-420.

33. Helmer SD, Hansen PJ, Anthony RV, Thatcher WW, Bazer FW, Roberts RM: Identification of bovine trophoblast protein-1, a secretory protein immunologically related to ovine trophoblast protein-1. J Reprod Fertil 1987, 79:83-91.

34. Flechon JE, Flechon B, Degrouard J, Guillomot M: Cellular features of the extra-embryonic endoderm during elongation in the ovine conceptus. Genesis 2007, 45:709-715.

35. Ullah Z, Lee CY, Lilly MA, DePamphilis ML: Developmentally programmed endoreduplication in animals. Cell Cycle 2009, 8:1501-1509.

36. Wooding FB, Flint AP, Heap RB, Morgan G, Buttle HL, Young IR: Control of binucleate cell migration in the placenta of sheep and goats. J Reprod Fertil 1986, 76:499-512.

37. Reimers TJ, Ullmann MB, Hansel W: Progesterone and prostanoid production by bovine binucleate trophoblastic cells. Biol Reprod 1985, 33:1227-1236

38. Matamoros RA, Caamano L, Lamb SV, Reimers TJ: Estrogen production by bovine binucleate and mononucleate trophoblastic cells in vitro. Biol Reprod 1994, 51:486-492

39. Gross TS, Williams WF: Bovine placental prostaglandin synthesis: principal cell synthesis as modulated by the binucleate cell. Biol Reprod 1988, 38:1027-1034.

40. Xie SC, Low BG, Nagel RJ, Kramer KK, Anthony RV, Zoli AP, Beckers JF, Roberts RM: Identification of the major pregnancy-specific antigens of cattle and sheep as inactive members of the aspartic proteinase family. Proc Natl Acad Sci U S A 1991, 88:10247-10251.

41. Hashizume K, Ushizawa K, Patel OV, Kizaki K, Imai K, Yamada O, Nakano H, Takahashi T: Gene expression and maintenance of pregnancy in bovine: roles of trophoblastic binucleate cell-specific molecules. Reprod Fertil Dev 2007, 19:79-90.

42. Talbot NC, Powell AM, Camp M, Ealy AD: Establishment of a bovine blastocyst-derived cell line collection for the comparative analysis of embryos created in vivo and by in vitro fertilization, somatic cell nuclear transfer, or parthenogenetic activation. In Vitro Cell Dev Biol Anim 2007, 43:59-71.

43. Parrow V, Horton C, Maden M, Laurie S, Notarianni E: Retinoids are endogenous to the porcine blastocyst and secreted by trophectoderm cells at functionally-active levels. Int J Dev Biol 1998, 42:629-632.

44. Erlebacher A, Price KA, Glimcher LH: Maintenance of mouse trophoblast stem cell proliferation by TGF-beta/activin. Dev Biol 2004, 275:158-169.

45. Whitley GS: Production of human trophoblast cell lines. Methods Mol Med 2006, 121:219-228.

46. Lafontaine L, Chaudhry P, Lafleur MJ, Van Themsche C, Soares MJ, Asselin E: Transforming growth factor Beta regulates proliferation and invasion of rat placental cell lines. Biol Reprod 2011, 84:553-559.

47. Arredondo J, Chernyavsky Al, Webber RJ, Grando SA: Biological effects of SLURP-1 on human keratinocytes. J Invest Dermatol 2005, 125:1236-1241.
48. Vukicevic S, Kleinman HK, Luyten FP, Roberts AB, Roche NS, Reddi AH: Identification of multiple active growth factors in basement membrane Matrigel suggests caution in interpretation of cellular activity related to extracellular matrix components. Exp Cell Res 1992, 202:1-8.

49. Koshi K, Suzuki Y, Nakaya Y, Imai K, Hosoe M, Takahashi T, Kizaki K, Miyazawa $T$, Hashizume K: Bovine trophoblastic cell differentiation and binucleation involves enhanced endogenous retrovirus element expression. Reprod Biol Endocrinol 2012, 10:41.

50. Hamilton DW, Allen WR, Moor RM: The origin of equine endometrial cups. 3. Light and electron microscopic study of fully developed equine endometrial cups. Anat Rec 1973, 177:503-517.

51. Ka H, Spencer TE, Johnson GA, Bazer FW: Keratinocyte growth factor: expression by endometrial epithelia of the porcine uterus. Biol Reprod 2000, 62:1772-1778

doi:10.1186/1477-7827-12-55

Cite this article as: Awad et al:: SOLD1 is expressed in bovine

trophoblast cell lines and regulates cell invasiveness. Reproductive Biology and Endocrinology 2014 12:55

\section{Submit your next manuscript to BioMed Central and take full advantage of:}

- Convenient online submission

- Thorough peer review

- No space constraints or color figure charges

- Immediate publication on acceptance

- Inclusion in PubMed, CAS, Scopus and Google Scholar

- Research which is freely available for redistribution 